International Journal of Agriculture, Environment and Bioresearch

Vol. 06, No. 01; 2021

ISSN: $2456-8643$

\title{
SOCIO-CULTURAL FACTORS OF THE PRACTICE OF ADULTERY AMONG THE FON IN ABOMEY
}

\author{
Charles Lambert BABADJIDE \\ Teacher at the Department of Sociology-Anthropology from the University of Abomey-Calavi (UAC) / Benin \\ https://doi.org/10.35410/IJAEB.2021.5602
}

\begin{abstract}
Sexuality is human and therefore it is subject to a rule which institutionalizes it. Adultery is a deviant practice in African and Beninese communities. The objective of this research is to analyze the socio-cultural factors of the practice of adultery in Abomey's dark environment. This research, essentially qualitative, made it possible to mobilize several actors who interact in the manifesto of this very frequent practice nowadays. From the reasoned choice technique, actors such as women who have committed adultery at least once, family members of husbands whose wife has committed adultery, populations, elders and local authorities often responsible regulation, were selected. Thanks to documentary research, observation and semi-structured interview, the information collected, analyzed and discussed have led to interesting results that provide information on the social and cultural reasons that facilitate, according to the respondents, the practice of adultery in Abomey's Fon environment. Likewise, certain consequences of this act are set out in this text with an outline of the institutions for regulating this practice, which was very tolerated in the Abomey background.
\end{abstract}

Keywords: Abomey, adultery, deviance, practice.

\section{INTRODUCTION}

Man is an essentially relational being and the place or even the medium of this deployment is the city. No humanity is possible in isolation. Its founding and even founding basis is the family, which constitutes the very first of social institutions. In this, it is said to be the basic cell of all human society. E. Durkheim (1909), attesting that the family is the basic unit of any society, states that "everyone, in principle, belongs to one family and founds another". This implies, apart from some physiological, socio-cultural and economic constraints, that every individual should be based on whatever his social status, his time and his region. Thus it calls for the institution of the marriage bond, whether modern or traditional, an institution which marks the beginning of a common life. The family then becomes the first society in which the individual lives; it is the basic social unit. As the first group to which any individual belongs, it determines the types of relationships that develop between the members that compose it. It is therefore a living social reality, which deserves attention in our societies, characterized by recent social upheavals. As a result, the role of the sociologist becomes essential in the analysis of the profound and irreversible transformations that Africa has been facing for years. 
Vol. 06, No. 01; 2021

ISSN: $2456-8643$

It is from this perspective that many sociologists see the family as a privileged place for social change. The changes that the world is experiencing, due to globalization and globalization, also affect families in Abomey. These social transformations constitute an obstacle to the development of these families and as said by KJHGanye (2012: 8), they are taking place in a context of changing values, underway in the city of Abomey, known for its strong anchoring in customs and traditions. Thus, the family fabric is increasingly experiencing various disturbances. Among these disturbances is the trend of adultery.

JF Guillaume (2016) underlines that the 17th century was marked by the phenomenon of passion-love, which for Descartes is natural, that is to say that it is linked to the mind and not to the body. . The concern then is often to control it. Gallantry, for example, tries to weaken passions through banter. This love, which was generally rather valued at the time, did not concern marriage. But at the same time, a trend is emerging that extramarital love is shameful. This is where the notion of adultery will follow. From the 17th century to the middle of the 18th century, S. Dayan-Herzbrun (1991) advocates a mechanical sexuality, of reproduction (dissociated from feelings), even if it is less evident. severe in relation to the pleasure of love when people are married, in order to avoid adultery. At the same time, sexuality was also minimized, and for reproductive purposes in the conception of the bourgeoisie. From the middle of the eighteenth century to the middle of the twentieth, the conception of the Church continued to advocate sexuality solely for the purpose of procreation, while a slight change was felt at the end of the twentieth century. Sexuality is then admitted if it is a manifestation of love and limited in marriage. But pleasure in itself is always rejected. The duty of procreation is minimized but the reproductive finality is still present. On the other hand, with regard to relations outside marriage of this time, JC Bologne (1998) recalls that: "the liberation of morals mainly concerned men, who seeks in a woman an object of pleasure and, if he is married, especially fears that his is one! The obsession with adultery, which alone occupies the entire third book of Rabelais, has never been so strong. A question of honor rather than love. This in fact is not necessary for the natural purpose of marriage, procreation"

C. Lévi-Strauss (1949) explains that "if the regulation of relations between the sexes constitutes an overflow of culture into nature, a beginning of social life (...).

It is in the area of sexual life, in preference to any other, that the passage between the two orders can and must necessarily take place. A rule which embraces what, in society, is most foreign to it: but at the same time, a social rule which retains, in nature, what is likely to go beyond it "(C. Lévi-Strauss, 1949: 14). The absence of guilt allows great freedom of gesture in heterosexual relationships, and frigidity and helplessness are almost absent. Sexual relations, in which the man is however always the initiator, take place, according to M. Mead (1963), in a harmonious way, but without jealousy and without passion. Adultery is punished only lightly, unless the culprit is the wife of a chief, in which case she risks being expelled from the village. She could also have recourse to divorce, simple and easy (M. Mead, 1963: 457).

From the work of C. Bounang Mfoungue (2012), it should be remembered that in traditional societies, adultery was harshly repressed: the people concerned were banished from the village. Women were required to confess the number of lovers they had in order to save their children and their own lives in difficult deliveries. If a woman is accused of adultery, the woman is held to swear on the fetish whether or not she has had adulterous relationships (C. Blanchard 1998: 97) .Bearing in mind the social relationships that exist between the spouses on the one hand and 
Vol. 06, No. 01; 2021

ISSN: $2456-8643$

between the spouses and the community on the other hand, adultery occupies an important place in the analysis of forms of instability within households. To this end, the analyzes of the family as a transforming social institution illustrate the work of crossing the individual and the collective, linking the microsocial and the macro-social put forward in sociology (A. Quéniart and R. Hurtubise, 1998). They add a link with "the privatization of family relationships and the decline in community, church and state controls."

In Abomey, under the pressure of dignitaries, religious and wise men, the arrangement of hennu (lineage) and Xwé (house) called Ako (large or extended family) allows a solidification of the marital bond for the benefit of social stability in Household chores. This goes through the repetitive nature of social referents (obedience, tolerance, morals, rites, totems and taboos ...) in the choices, decisions and orientation of the life of a couple. And as a result, the frequency of adultery and other forms of instability within households do not spare the people of Abomey. JH. Déchaux (2007) postulates that "the greater frequency of marital breakdown attests to the extent of individuals' expectations with regard to married life". Adultery therefore becomes an element of analysis of social control and social benchmarks within traditional societies. We must therefore give a special place to his analysis in a society like that of Abomey. This allows the debate to be raised to the rank of science. And at this level, it becomes important to open up other perspectives on adultery that go beyond those hitherto explored by psychologists, lawyers.... It is then up to researchers, particularly those in the humanities and social sciences, to make a significant contribution in the analysis of adultery and the social referents intervening in this field within traditional society. It is obviously in this perspective that This production is part of which the main question arises as such: what socio-cultural factors of the practice of adultery of women in the Abomey Fon environment?

\section{RESEARCH FRAMEWORK}

A historic city, the municipality of Abomey covers an area of $142 \mathrm{~km}^{2}$. It is bounded to the north by the commune of Djidja, to the south by the commune of Agbangnizoun, to the east by the commune of Bohicon and to the west by the commune of Aplahoué. It has seven (07) districts subdivided into twenty-nine (29) city districts and villages. Its human density is 468 inhabitants / $\mathrm{km}^{2}$. The population of the commune of Abomey is mainly made up of Fon. This commune is a locality where ancestral practices are still prevalent insofar as the influence of traditional religious leaders is undeniable in all districts. However, we observe the cohabitation of several religions. All of this information provides information on the social dynamics influencing the experience of adultery in the municipality of Abomey. The choice of Abomey therefore constitutes a fairly representative cluster for a study of adultery in Benin.

\section{MATERIALS AND METHODS}

The analysis of the socio-cultural factors of the practice of adultery among women in the Abomey background is intended to be qualitative research to clearly highlight the perceptions of the people targeted. This made it possible to understand their opinion on the subject. Since the collection of empirical data cannot reach the entire population, recourse to the reasoned choice sampling technique was used to define the research sample. It made it possible to take into account research units made up of married women, adulterous women, traditional healers, 
Vol. 06, No. 01; 2021

ISSN: $2456-8643$

religious leaders, tangninon, male victims of adultery and the immediate entourage of victimized couples. Fifty-two (52) people were selected. These actors are identified, for the most part, by reasoned choice. The selection criteria vary according to the categories of actors. The main criteria take into account the experience of religious leaders in resolving marital disputes. Also, from discussions with the immediate entourage of couples who were victims of adultery, some situations were identified that could lead to adultery. Each category of actor is associated with an initial outline in terms of the types of information expected. Three data collection techniques were employed to complete the empirical data collection. It is about documentary research, semistructured interviewing and observation.

The data collected is structured so that it can be analyzed efficiently. The first stage of this work consists of the complete transcription of the information collected from each person interviewed. Then followed the data processing. To do this, the information collected through the interview guides was subjected to processing which consisted of looking for similarities in the descriptions and of categorizing them by axis of analysis and of synthesizing them. The structuring of qualitative data seemed demanding in thought and also required enough time. The content analysis was used to categorize the information from the interview guide. These analyzes followed the axes of the structuring made during the treatment; it consisted of a comparative cross-referencing of information, either within the same category of actors, or between categories; then to make a comparison of the elements emerging from the analysis with the trends emerging from the literature.

\section{RESULTS AND DISCUSSION}

\subsection{Adultery in a "Fon" environment}

The nature of certain facts or acts makes it impossible to better explain them to see clearly. Several perceptions were gathered in the field but none was unanimous and validated by all. Each gives his point of view according to the realities of his environment and according to his level of understanding of the facts. Following the question about what adultery is, various responses were gathered. Given the diversity of opinions of our respondents on adultery, it was found that it is difficult to give reliable explanations of this act in our traditional societies. Thus, among the Abomey "fon" adultery is seen as a source of social instability, a crime on the clan level. Adultery had been around since the days of ancestors, and when it was committed no one forced their hand until it was revealed at the risk of losing their lives. For many interviewees, adultery is seen as most social acts to which the African tradition finds it difficult to explain and which can be immune to criticism. Adultery among the Abomey "fon" is generally viewed in a variety of ways. Thus, for some respondents,

"Adultery commonly known as (afodogbé) in the Fon language has three levels: The first is when a married woman shows her nudity to another man. The second is the fact that a married woman lets her pearls, even her thighs, be seen by another man. The third and most crucial is the fact that a married woman has sexual relations with a man other than her spouse ". [Interview with Dah HOUDALIHO bokonon 65 years old, married and father of twenty eight children.]

Still in the same vein, a Tangninon explains that: 
"The afJdogbé is a very sensitive and delicate fact. When a married woman shakes hands with another man, sitting on the same bench with a man other than her spouse, she is considered an adulteress. She specifies that the most delicate is the fact that a married woman has sexual relations with a man other than her spouse ". [Interview with L. G. Tangninon 86 years old, widow and mother of two children.]

In other families, a married woman is not even allowed to talk to her ex and worse yet to take money from the ex. A dah among the ANANNOU added by saying:

"I received a case the last time the woman had a fertility problem and following the revelations of the 'fâ', the woman would have committed adultery and without her confession, she might look for pregnancy. But in reality she hadn't gone to sex with a man. It was her ex whom she had met one day on the road to the market and who had given her five miles. Ignorant though she was, she spent what she had and even the five miles without saying a word to her husband. Which brings him misfortune "[Interview with dahAhononvi 64 years old, married and father of seven children.]

These responses on adultery make it possible to understand that among the Abomey "fon", the way of conceiving of adultery reveals the influence of social and endogenous values in the lifestyles of families. Indeed, the social changes experienced by Dahomey after its independence have caused profound upheaval in families. This upheaval has not spared the way of life of women in households. Thus, the latter behave in a vulgar manner unlike the life led by the woman of yesterday, that is to say the woman in pre-colonial society. This is reflected in their clothing and daily habits. This lifestyle is not without impact on the viability of couples. However, in the African tradition, totems and taboos form part of the rules according to which married women must walk for the proper functioning of their homes. This leads to many cases of adultery nowadays because the current generation ignores the merits of these totems and behaves as they see fit.

Thus some women, banally commit adultery through their behavior without realizing it. It should be noted that the most important thing is to go to sex with a partner other than his spouse. But this is still not the case. Because for Anne Martin-Fugier (2014) "Two beings, of different sex, locked in a room with only one bed was enough to constitute the crime of adultery". Then adultery becomes a sensitive and difficult act to accept. It is considered a crime, a serious sin on a family or clan level. As R. Garofalo (1885) said, crime is a harmful action that damages human morals. It is a violation of acquired moral feelings. Feminine adultery is outlawed in Fon circles, because the "gnonnuhwési" woman is considered to be made for the house and for one man. Adultery in women is recognized as a source of instability and a curse for "Hennu" (the community). So for some respondents, the toxwy would be very jealous. He doesn't allow a woman in his dealership to look elsewhere. If one of his wives commits adultery, his anger springs up on the home and on the whole family. And when you don't quickly beg your forgiveness, the damage follows.

\subsection{The social causes that justify adultery among women in a "dark" environment}


There are several reasons for a woman's infidelity. They are multiple and multifaceted and depend on each situation. Table I presents some of the reasons that lead the "fon" woman to adultery in Abomey.

Table I: Table relating to the reasons for adultery in Abomey

\begin{tabular}{|l|}
\hline Reasons mentioned \\
\hline Sexual dissatisfaction \\
\hline Inordinate ambition \\
\hline Poverty \\
\hline Lack of attention \\
\hline Insatiable woman \\
\hline The weight of religion or the ignorance of tradition \\
\hline Polygam \\
\hline Service relationship \\
\hline Domestic violence \\
\hline
\end{tabular}

Source: Field results (2019 survey)

The variables reported in the previous table are retained following the research interviews and the conceptualization of the discourse and life stories recorded. Nine variables have been identified for this purpose, and represent points of contention between the spouses, as they are considered intolerable.

\section{Sexual dissatisfaction}

One of the major taboos of our different cultures is sex. Couples do not escape this taboo, which is often a source of devious and imperceptible conflicts. Most of the differences in couples are more or less closely related to sexual difficulties. The sexual dissatisfaction of one of the partners leads to cases of infidelity in the household. Along these lines, it was revealed that:

"A man has a duty to satisfy his wife's sexual needs, because the housewife is not an object to be contemplated and vice versa. Otherwise, disagreements set in and welcome infidelity. But there are others who are naturally insatiable when it comes to sex drive and whatever their partner does to them, they will always get to taste elsewhere. " [Interview with dah METOKAN, Bokonon 47 years old, married and father of seven children.]

From these words, we understand that among the most pressing needs of the couple is sexual relations. In the event of a defect in one of the spouses, the second easily indulges in infidelity in order to satisfy his libido. Also, some, despite their partner's sexual efforts, are never satisfied. So, to satisfy this need, they embark on other romantic adventures. However, it is not only the sexual deficit in marriage that induces in this adventure of infidelity but the fact of wanting to give oneself pleasure and also to find in this activity a passion can also be at the base of this offense. To this end, O. Dima (2010) considers adultery to be a physical, emotional, spiritual and 
Vol. 06, No. 01; 2021

ISSN: $2456-8643$

social necessity. He indicates in his analysis that adultery is a necessary substitute for some important aspects of life, often missing in marriages. These missing aspects can be passion, desire and pleasure.

Ultimately, adultery not only serves to satisfy sexual thirst, but also serves to fulfill passion, desire and pleasure.

\section{Inordinate ambition}

There are women who have the minimum that their husbands offer them, but they envy the fate of their fellow man and deplore their living conditions. So they are dissatisfied and will have extramarital affairs with wealthy men just to be able to appear, dress expensive in designer clothes, have shops etc ... to the detriment of their husbands.

"I have a sister who separated from her husband because of the fact that we have cousins who have married great men, who have cars, beautiful houses, who dress well and the list does not is not exhaustive. But she was married to a simple trader and that hurt her too much. She was embittered and complained every time about her situation. So she started out by cheating on her husband with super wealthy men and it worked out well for her since she has several lovers at the same time and she lacked nothing. »[Interview with A. E. 28 years old, housewife, married and mother of three children.]

Through this statement, we see that money is such an important element that leads to adultery. The search for easy gain and a somewhat high social class of some married women draws them into the arms of other men whose conditions are better than those of their husbands. This surely leads to divorce. And being divorced, the woman feels free from any commitment. Thus she pursues her ambitions by giving herself the privilege of having romantic relationships with several men at the same time. In this way, the consequence of her adultery is similar to what HJ Neuschäfer (1989: 39) speaks of, who in his analysis shows how female adultery becomes a kind of liberation which helps to make the woman more independent. But this life of debauchery is not without consequences on her health as she is exposed to sexually transmitted diseases such as HIV AIDS. And also on her dignity, may she become the laughing stock of society and the gaze towards her changes.

\section{Poverty}

The most common case is the lack of financial means, the fact that the man does not have the necessary financial means to take care of his wife, the latter accepts without thinking the advances of another man who can offer her the material and financial comfort she needs.

Other women to help their husbands and feed the children engage in infidelity in order to find the minimum to meet the daily needs of their household. One interviewee told us about this situation:

"My husband has been unemployed for years. We find it difficult to meet our daily needs. It's hard for him to give me a thousand francs for meals and sometimes tell me to make do with it for at least a week. The children are there, they are hungry. How am I going to do? I have to go on 
Vol. 06, No. 01; 2021

ISSN: $2456-8643$

other adventures, I go out with my arms dangling and come back with sachets full of food and my husband eats well without questioning. " [Respondent F. 2019]

Analysis of these comments shows that poverty makes some women more likely to engage in actions that may be considered adultery. In this specific case we can speak of an occasional prostitution which is also a form of adultery that the day she is caught, she will be considered an adulterous woman and will suffer the same fate as the one who made her of his will. But to say that because of the lack of financial means, she tastes elsewhere to satisfy the daily life of her household, is an excuse to camouflage her nature as an unfaithful wife because there are a thousand ways to solve this problem.

\section{Domestic violence}

Domestic violence is such an important factor that can lead to infidelity in the home. This state of affairs is explained by the fact that there are some women who suffer humiliation from their husbands. They beat them whenever the opportunity presents itself. This behavior is likely to push the woman into adultery, which she exploits as an opportunity to return the blow to her spouse.

"I have been unfaithful, and if I was, it is because the gentleman that my in-laws proposed to me as my husband and who was the younger brother of my late husband, because I did not the right to leave the family after the death of my husband, keeps beating me up whenever there is an argument between us. This humiliation that I suffered from the latter revolted me to the point where I decided to mark the cost of him by going to sleep with another man. "[Interview with A. B. 39, housewife, married and mother of five children.]

To this end, M. Barošová (2009: 27) describes how the forced marriage, without love, accentuates the differences between the two beings, which results in a total incomprehension in the couple. M. Barošová (2009: 32) finds that the reasons for cheating are the disagreement between the spouses, the lack of love, the desire to change the monotonous life, a way of revenge against the indifference of the husband. So it is understood through these words that a marriage founded without love and without consent often leads to conflicts between the two spouses. Indeed, the man being a being naturally stronger, more dominant than the woman, abuses this force to humiliate it by mistreating it. For him, the woman is an inferior being who has no right to express herself. However, women also have natural assets which give them courage and value. So she decides to show her ability by cheating on her husband. But this method of revenge is not the best as it has negative consequences for the education of children.

\section{The influence of religion or ignorance of tradition}

One of the reasons for the growth of the phenomenon is the all-out creation of certain imported religions because they deny the existence of the traditional family and refuse to be a member. The leaders of these religions teach the faithful to deny their origin and cling only to God. So for the latter, there is no confession to be made in front of any head of the family. Thus, all the excesses of the couple are managed by the religious leaders. And in the name of religion, many women commit adultery and refuse to confess and ultimately death follows. As E. Kant (1724- 
1804) said "Religion, without moral conscience is only a superstitious cult. We believe that we are serving God when, for example, we praise him or celebrate his power, his wisdom, without thinking about how to obey divine laws, without even knowing and studying this wisdom and this power ". K. Marx (1818-1883) attests to this by saying that "Religion is the sigh of the oppressed creature, the soul of a heartless world, as it is the spirit of social conditions from which the spirit is excluded. It is the opium of the people ". He always explains that religion is both a remedy that can either alleviate our suffering or lead us to healing, but it is also a poison that affects our ability to think and puts us to sleep. So praising God is not enough. We must also obey the laws of nature. That is, to act according to the norms of society.

The other aspect of the phenomenon is the fact that some men do not bring their wives to their families to undergo the various prescriptions. Thus the woman considers herself free from any traditional commitment, and not accountable to someone, they indulge in these unorthodox practices which subsequently have enormous consequences on their lives as well. than that of their husbands.

\section{Polygamy}

Polygamy allows a man to have several wives. Some co-wives sometimes live under the same roof, which sometimes causes tension. Jealousy, rivalry, war between co-wives, neglect of a woman for the youngest set in. Thus, conflicts escalate and it is especially when the husband takes sides with one of them. Polygamy is then an aggravating factor of adultery because the neglected woman seeks her consolation in the arms of another man. Polygamy, seen as a cure for adultery, ended up being its own cause.

\section{Lack of attention}

The fact that a woman lacks caring, affection and love can cause her to be unfaithful. Indeed many women are married to businessmen and who often do not have time for their wives, others on the other hand are not busy but do not show any attention to their wives. These when they come out of the house and a man advances to them with compliments, they easily throw themselves into his arms because they just found that affection they lacked. According to Charvier-Berman, (1989: 45) "If marriage is compulsory, adultery is the place of freedom." $\mathrm{He}$ explains in these terms that adultery is a kind of heavenly place where women can be free and passionate.

\section{Insatiable women}

Some men who have married women who like to go out, have fun in a nightclub, etc ... while these men do not like going to these places, so they sneak up on boyfriends (big in size, very handsome and well-built) to show off, to be fashionable. It should be noted then that these women, despite their husbands' attention, still continue to cheat because they are used to this way of life, and find it difficult to give up so easily.

\section{Service relationship}


The adulterous relationships of women often take shape in their places of service, either with the colleague, or with the boss, or with a client of the company. By dint of rubbing shoulders every day, having lunch together, discussing, laughing during break times, it can create feelings between the two (married woman and her colleague) since they realize that they have a lot of things. in common, they start with regrets like why I didn't know you early on? It is perhaps to avoid this kind of situation that some men do not allow their wives to practice a professional activity regardless of the diploma they have.

Adultery as a breach of faith, of the obligation of fidelity and of the dignity of marriage, has enormous consequences on the life of the perpetrator, her husband, her children and even those around her.

\subsection{The social consequences of adultery}

Indeed, when a married woman commits adultery, the direct result is that the couple as well as the two allied families are not only divided but also weakened because a climate of doubt and mistrust sets in between the two spouses and families. The trust that existed in the beginning disappears completely to the point where conflicts take place. The education of children also receives a blow and fails under these conditions, so much so that they are left to their fate and become the laughing stock of society. The corollaries that flow from these conflicts are numerous. The most common are shown in Table II:

Table II: Table relating to the consequences of adultery in Abomey

\begin{tabular}{|l|}
\hline Direct consequences on the couple \\
\hline Divorce \\
\hline Alcoholism of being deceived \\
\hline Lack of peace in the marital home \\
\hline Distrust \\
\hline The fall in activities \\
\hline Consequences on women \\
\hline Weakening of the links between daughter-in-law and in-laws \\
\hline Stigma vis-à-vis the adulterous woman \\
\hline Loss of dignity of the adulterous woman \\
\hline Lack of consideration for the adulterous woman \\
\hline Consequences on children \\
\hline Discrimination against children \\
\hline Delinquency \\
\hline Rejection of the entourage \\
\hline Social consequences \\
\hline Disruption of social cohesion \\
\hline Cultural consequences \\
\hline
\end{tabular}


Vol. 06, No. 01; 2021

ISSN: $2456-8643$

\begin{tabular}{|l|}
\hline The onset of diseases of unknown source \\
\hline The death \\
\hline The wrath of traditional deities \\
\hline
\end{tabular}

Source: Field results (2019 survey)

\section{Divorce}

Divorce is a momentous decision, one that has never been better handled by spouses. It is the direct consequence of adultery and constitutes a painful upheaval for the couple's entourage and an attack on social cohesion. It is the legal realization of a de facto situation in the making, but also and above all of what is the cause: the couple's difficulties and the slow or brutal breakdown of the conjugal and family unit. In the phenomenon of divorce, everyone is at the same time for their part and for a part victim and executioner. Children know the repercussions and are often affected by their parents' divorce, which leads them into delinquency, and trauma sets in. Indeed, adultery and infidelity are two variables subject to 'a request for divorce. But they are not seen in the same way. May in Abomey the expression "Sunnuglégbénu" attributed to men give them the privilege of committing infidelity with ease or confidence (you have to be a weak man or a helpless to know a single woman). The expectations of the housekeeper are too much and force the man to resort to infidelity. But this infidelity often leads to divorce when it is carried out within the wife's family (sister, cousin ...). As for adultery or infidelity of the woman, this is forbidden among the "fon" because the "gnonnuhwési" woman is made for the house and belongs to one man. Adultery in women is considered to be a source of instability and a curse for "Hennu". So resorting to divorce becomes important to spare this woman from the damage that the anger of the ancestors can cause.

\subsection{Effects on the family of the adulterous woman}

Single men who heard the news are reluctant to enter into a romantic relationship with a daughter coming out of the guilty woman's family. They say to themselves that all the women from this family will have the same education. Thus, they have difficulty in finding a husband in the locality and its surroundings.

To remedy the evolution of this scourge which undermines our African customs and culture, means are put in place in our societies to make women aware of the merits of living as a couple and also to show women that 'she is the pillar of marriage, that it is necessary for her to remain faithful to her man. Also means are put in place to grant forgiveness in the event of infidelity among women. To this end, in certain families among the "fon", when the wife commits adultery, and the husband still cares about her, there are steps he takes to ask for the clemency of his family, especially that of the gods. of his concession for the maintenance of peace within his home and within society. This calls for the commitment of midwives and other women in the community in favor of the "afjlile" ritual for the purification of women.

\subsection{The role of actors intervening in the reintegration process of adulterous women}

The existence of any society, whether archaic or modern, involves the distribution of roles and statuses to the different members that compose it. These roles are determined by various factors 
(socio-economic and cultural) which vary over time. In other words, the place occupied by each other is not absolute but relative. Roles according to M.Blouin (1995) refer to "a set of standards and expectations which govern the behavior of an individual because of his social status or because of his function in a group". As for the social role, for H. Amouzouvi (2011), it is about the set of behaviors conducted in relation to a person within a group. Thus, social roles are, according to Linton, attached to the status of the individual within a social system. So following the expressions of H. Amouzouvi (2011), status is the place an individual occupies in a group of individuals, in a social system. Thus, the husband of the adulterous woman, given his status visà-vis the home and being the first to be aware of the situation, has the obligation to bring the information to the family level. He therefore informs the elder of his concession. Therefore, the husband and his eldest are the first actors involved in initiating the process, because they are the first to be aware of the situation. From that moment on, a set of actors sets in and various actors interfere in the process.

In Abomey, there is the intervention of resource persons such as the Hennuto, whose function is to bring the whole court together by putting them in touch with the news. In this same wake, there are certain actors who are present alongside the Hennuto in order to serve as an advisor, and better still, to stand face to face with the couple but separately. They also have the task of recalling the prescriptions, the prohibitions of the house. They are the Tangninon and the houessi. The Bokonon intervenes when the woman denies the facts. So that the "fâ" can clarify the situation. From this moment there is the intervention of actors such as Towxyonon, Towxyossi and Hounsso whose main function is to purify the adulterous woman. This through "intermediaries between the woman and the ancestors" such as the goat, the hen, the rooster, the colas, the "ata and ovi", the bottles of sodabi and candy etc ..., used during the purification ceremony. The brothers and sisters of the husband (the victim) are there to assist him morally as well as the parents of the wife (the culprit) to assist him during the period of his reintegration. Everyone positions themselves according to their importance in the community.

\section{Table III: Summary of the positions of the Actors}

\begin{tabular}{|c|c|}
\hline Main actors & Essential actors \\
\hline $\begin{array}{l}\text { - The adulterous woman } \\
\text {-The husband }\end{array}$ & $\begin{array}{l}\text { - } \text { The Hennuto } \\
\text { - } \text { The Tangninon } \\
\text { - } \text { The Towxyonon } \\
\text { - } \text { the Towxyəssi }\end{array}$ \\
\hline Intermediate actors & Actors present \\
\hline $\begin{array}{l}\text { - The eldest of the husband's } \\
\text { family conception } \\
\text { - The parents of the adulterous } \\
\text { womanLes frères et sœurs du } \\
\text { mari }\end{array}$ & $\begin{array}{l}\text { - } \text { - The houessi } \\
\text { - } \quad \text { The Hounsso }\end{array}$ \\
\hline
\end{tabular}


Vol. 06, No. 01; 2021

ISSN: $2456-8643$

Source: Field data (2019 survey)

The analysis of the acting shows the importance of carefully examining the roles of certain actors considered essential in the process of purification of the adulterous woman in a "fon" environment in Abomey such as the Hennuto, the Tangninon, the Təwxyənวn, the Təwxyəssi

Here, the houessi, the Hounssos are actors present on the day of the ceremony who also have their share of responsibility. The eldest of the husband's family conception, the wife's brothers and sisters are here as intermediary actors, because the eldest of the husband's family conception is the intermediary between the husband and the head of the community. , the parents of the woman as representative of the family of the adulterous woman. As for the main actors, namely the adulterous woman (the person committing the act "the culprit") and the husband (the betrayed person "the victim"), apart from the yes "I want to keep my wife" from the husband is that is to say his decision to implore forgiveness for his wife, and the acceptance of the woman to be purified, all the steps which will follow will be the responsibility of the various actors mentioned above. Among these actors identified in the process of reintegration of the adulterous woman, each has his or her role in it.

\section{CONCLUSION}

The family is a social entity which initiates, educates and socializes the human being. Man and woman unite for life and owe each other loyalty. This union contains within it all the components of an organized living environment for the individual, a framework made up of solidarity and social protection. A framework based on the influence of social and endogenous values on the lifestyle of couples in Abomey. But with the social transformations observed in recent years, the contemporary family is faced with new dynamics that upset its stability. These dynamics are the basis of many abuses within the family. Adultery, a form of marriage drift is variously perceived in Benin and more particularly in Abomey. The view of Abomey's "fon" culture on this phenomenon varies from one concession to another. This is a phenomenon which remains and remains a sensitive point on which the intervention of social actors remains to be resorted to because when a woman commits adultery, she is faced with enormous consequences, including "the anger of the ancestors".

\section{REFERENCES}

Amouzouvi Hyppolyte, 2011, "The religious references of pain among parturients in Cotonou: elements for a sociology of childbirth", in Revue semestrielle de Géographie du Bénin, ISSN 1840-5800, No. 10 December.

Barošová Michaela, 2009, The image of women and love in Guy de Maupassant's tales and short stories. Thesis from the Faculty of Philosophy of Masarykova University, Brne, Czech Republic

BLANCHARD Christopher, 1998, The so-called "Anyi de Krinjabo" statues in the terracotta statuary of the south-eastern quarter of the Ivory Coast: stylistic and historical study, University of Paris1. 
BLOUIN Mathieu, 2005, The influence of the fulfillment of promises made to employees on organizational commitment: the moderating effect of employment status. 2005.

BOLOGNE Jean-Claude, 2004, History of celibacy and celibacy. Fayard.

BounangMfoungué Cornelia. African marriage, between tradition and modernity: socioanthropological study of the couple and marriage in Gabonese culture. Sociology. Paul Valéry University - Montpellier III, 2012.

Charvier-Berman Evelyne, 1989, "Maupassant short story writer: female character and adultery". Frozen Words $n^{\circ} 7$ (1), pp. 43-50.

Dayan-Herzbrun Sonia. Sexuality in the light of the social sciences. In: Social sciences and health. Volume 9, $\mathrm{n} \circ 4,1991$. Sexuality and society. pp. 7-22; doi: https://doi.org/10.3406/sosan.1991.1206

DÉCHAUX, Jean-Hugues, 2007, Realities and limits of family mutual aid. Rethinking solidarity. The contribution of social sciences, Paris, PUF, p. 205-217.

DimaOana 2010. "Adultery at Maupassant". Communication, context, interdisciplinarity, $\mathrm{n}{ }^{\circ} 1$ 2010, pp. 258-263.

DURKHEIM Emile, 2020, Education and sociology. Good Press.

GANYE Karen J. H., 2012, master's thesis, University of Abomey Calavi, p: 08.

GARÓFALO Raffaelle, 1885, Criminología: estudio sobre el delito, sobre sus causas y la teoría de la represión.

GuillaumeJean-François, 2016, The experience of unfaithful loves: a form of commitment ?, Discussion of Marie-Carmen Garcia's book Amours clandestines. Sociology of durable extraconjugality, Lyon, PUL.

KANT Emmanuel, 1983, Foundations of the metaphysics of mores, trad. V. Delbos, Paris, Delagrave, vol. 1, no 969, p. 99.

LÉVI-STRAUSS, Claude, 1949, "Symbolic efficiency". Review of the History of Religions, p. 5-27.

MARTIN-FUGIER Anne, 2014, from Labourgeoise. Grasset.

MEAD Margaret, 1963, "Mores and sexuality in Oceania". French Review of Sociology, Vol. 4, no 2, p. 224.

Neuschäfer, Hans-Jörg, 1986, "The decline of the patriarchy. Adultery and divorce in the 1884 soap opera ". Popular Literature, ${ }^{\circ}{ }^{53}$, pp. 37-48.

QUÉNIART Anne and HURTUBISE Roch, 1998, "New families, new challenges for the sociology of the family". Sociology and societies, vol. 30, no 1, p. 133-143. 